\title{
ЭКОНОМИЧЕСКОЕ УПРАВЛЕНИЕ СЕГМЕНТАМИ БИЗНЕСА ПРОМЫШЛЕННЫХ ПРЕДПРИЯТИЙ
}

\author{
(c) 2018 Смирнова Елена Викторовна \\ доктор экономических наук, профессор \\ Оренбургский государственный университет \\ 460018, г. Оренбург, просп. Победы, д. 13 \\ E-mail: uadsev@mail.ru \\ (c) 2018 Цыганова Ирина Юрьевна \\ кандидат экономических наук, доцент \\ Оренбургский государственный университет \\ 460018, г. Оренбург, просп. Победы, д. 13 \\ E-mail: iren23_83@mail.ru
}

Тенденции современных процессов трансформации социально-экономических отношений в России и создания гибких систем управления бизнесом, которые способны обеспечить динамизм, адаптивность к внешней среде, а также конкурентоспособность промышленных предприятий определили необходимость решения проблемы экономического управления сегментами бизнеса через реализацию соответствующего механизма, включающего, в том числе, систему показателей оценки эффективности в разрезе плановой, организационной, мотивационной и контрольной функциональных подсистем, что обусловило актуальность тематики исследования как в теоретическом, так и практическом аспектах.

Ключевые слова: экономическое управление, механизм экономического управления, сегменты бизнеса, система показателей.

Современное состояние экономики России диктует особые требования к управлению как промышленным предприятием в целом, так и его сегментами бизнеса. Поддержка каждого из сегментов бизнеса отвлекает ограниченные ресурсы, которые могли бы быть направлены на достижение прочих (социальных, экологических, научно-технических и др.) целей. В связи с этим актуальными становятся формирование механизма экономического управления сегментами бизнеса и разработка методики оценки его эффективности на основе информации о текущих и прогнозируемых результатах деятельности промышленного предприятия с учетом изменений во внешней среде. Это предполагает разработку отдельных программ развития каждого из сегментов бизнеса.

В условиях высокой неопределенности внешней среды, вызванной активными изменениями ее составляющих, в практике управления решения зачастую принимаются в процессе/режиме ситуационного управления по мере возникновения проблем в соответствии со складывающейся экономической ситуацией. Это может происходить спонтанно, основыва- ясь на понимании и субъективном восприятии сложившейся ситуации, а также суммы знаний в конкретной области деятельности и накопленного опыта лиц, принимающих управленческие решения. Четкий алгоритм принятия таких решений отсутствует. Они не имеют под собой научно-обоснованных экономических расчетов и выводов, отсюда возможны неверные решения и в итоге отрицательные результаты деятельности. Это подтверждается статистическими данными о росте удельного веса убыточных предприятий в России за последние 10 лет. В январе-июле 2018 г. прибыли предприятий (в текущих ценах в годовом выражении) выросли больше $(+33,0 \%)$, чем убытки (+24,6\%), однако доля убыточных предприятий увеличилась и достигла $31,8 \%$ от общего количества зарегистрированных [1].

В промышленности сложившуюся ситуацию можно объяснить тем, что предприятия за последние годы столкнулись со множеством проблем, таких как: наличие непрофильных производств, низкий уровень их загрузки, физический и моральный износ основных фондов, ограниченность финансовых ресурсов, недостаток квалифицированных рабочих, и, как следствие, 
низкая конкурентоспособность промышленной продукции, что подтверждается статистическими данными об основных факторах, сдерживающих производство (рисунок 1).

Улучшение качества принимаемых управленческих решений и их эффективная реализация путем преодоления сложности проблемных ситуаций, обусловленной большим количеством взаимодействующих факторов и причинно-следственных связей, возможны с использованием механизма экономического управления предприятием, что может существенно облегчить деятельность руководителей и обеспечить результативность их работы.

Экономическое управление - один из видов управления предприятием в зависимости от объекта управления и методов, используемых в управлении. Именно экономическое управление предприятием позволит менеджменту принимать эффективные управленческие решения на основе предварительно выполненного анализа и экономических расчетов.

Теоретические и практические аспекты экономического управления предприятиями представлены в научных работах и публикациях ряда авторов. Так, Бездудная А.Г., Кадырова О.В. и Лебедев В.Г. [3] рассматривают два уровня экономического управления предприятием: внешнее (государственное) и внутреннее. Содержание экономического управления промышленным предприятием, по их мнению, сводится к систематическому анализу хозяйственной деятельности и финансового состоя- ния, определению показателей производства и эффективности использования ресурсов. Экономическое управление предприятием авторы связывают с производственным и организационным управлением. Коротков Э.М. [4] понятие экономического управления предлагает дополнить в связи с изменениями систем и структур управления, которые произошли по следующим направлениям:

- переход от узкой функциональной специализации к интеграции в содержании и характере управленческой деятельности, процессным организационным структурам;

- трансформация организационных структур предприятий из пирамидальных в плоские, усиление горизонтальных связей в них;

- осуществление децентрализации ряда функций управления;

- повышение роли инновационной деятельности и венчурного финансирования;

- создание «обучающихся» и «самонастраивающихся» предприятий.

Жданов С.А. [5] предлагает сущность экономического управления рассматривать с учетом обеспечения необходимого взаимного соответствия экономических элементов в функциональных зонах предприятия.

Первостепенными и наиболее общими задачами экономического управления предприятием являются:

1) выбор и применение наиболее эффективных методов и инструментов по сбору, учету и анализу информации для принятия управлен-
Обрабатывающие пронзводства

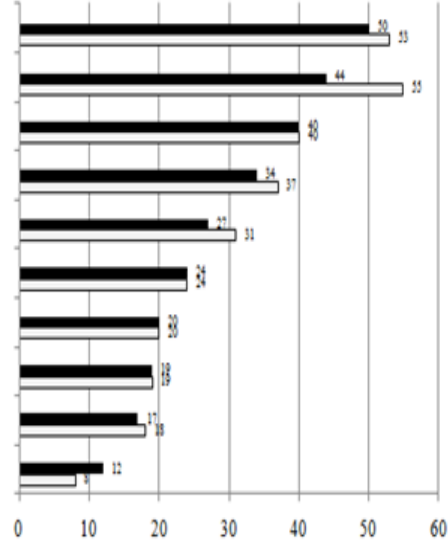

Недостаточный спрос на продуқиюю на внутреннем рынке Неотределнность якономической ситуации Высокий уровень налогообложения Недостаток финансовых средств Высокий процент коммерческого кредита Недостаточный строс на продуқцию на внешнем рынке Недостаток квалифицированных рабочих Конкурирующий импорт Изношенность и отсутствие оборудования Ограничений нет Добывающие пронзводства

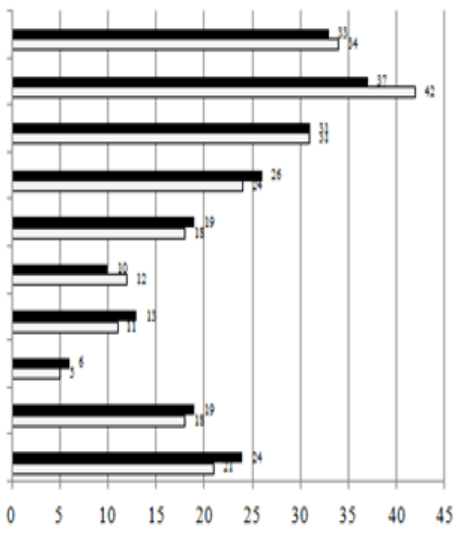

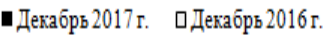

Рис.1. Факторы, ограничивающие деятельность промышленных предприятий (доля от общего числа обследованных предприятий,\%) [2] 
ческих решений;

2) своевременное предоставление необходимого объема информации для оперативного анализа и принятия управленческих решений.

Механизм экономического управления является неотъемлемым условием его реализации на предприятии. Он позволяет наполнить содержанием процесс экономического управления за счет применения соответствующих особенностям предприятия методов, используемых в подсистемах экономического управления для выполнения его функций. В механизм экономического управления входят: аппарат выработки целей и задач функционирования предприятия; функции и методы экономического управления. Рыжова В.В. [6] относит к главным функциям экономического управления предприятием: организацию управления; планирование; анализ; информационное обеспечение; контроль; мотивацию труда. Обобщив авторские положения
[7], [8], [9], [10], раскрывающие содержание понятия, под механизмом экономического управления предприятиями будем понимать комплекс целеориентированных средств воздействия и технологий, объединенных в единую систему экономического управления и обеспечивающих реализацию его функций для достижения наибольших экономических и иных результатов перспективного развития промышленного предприятия.

Реализация каждой из функций экономического управления предприятием предполагает использование соответствующего ей инструментария. Поэтому целесообразным представляется выделение в механизме экономического управления предприятием в качестве основных функциональных плановую, организационную, мотивационную и контрольную подсистемы (рисунок 2).

Виды экономической деятельности, осу-

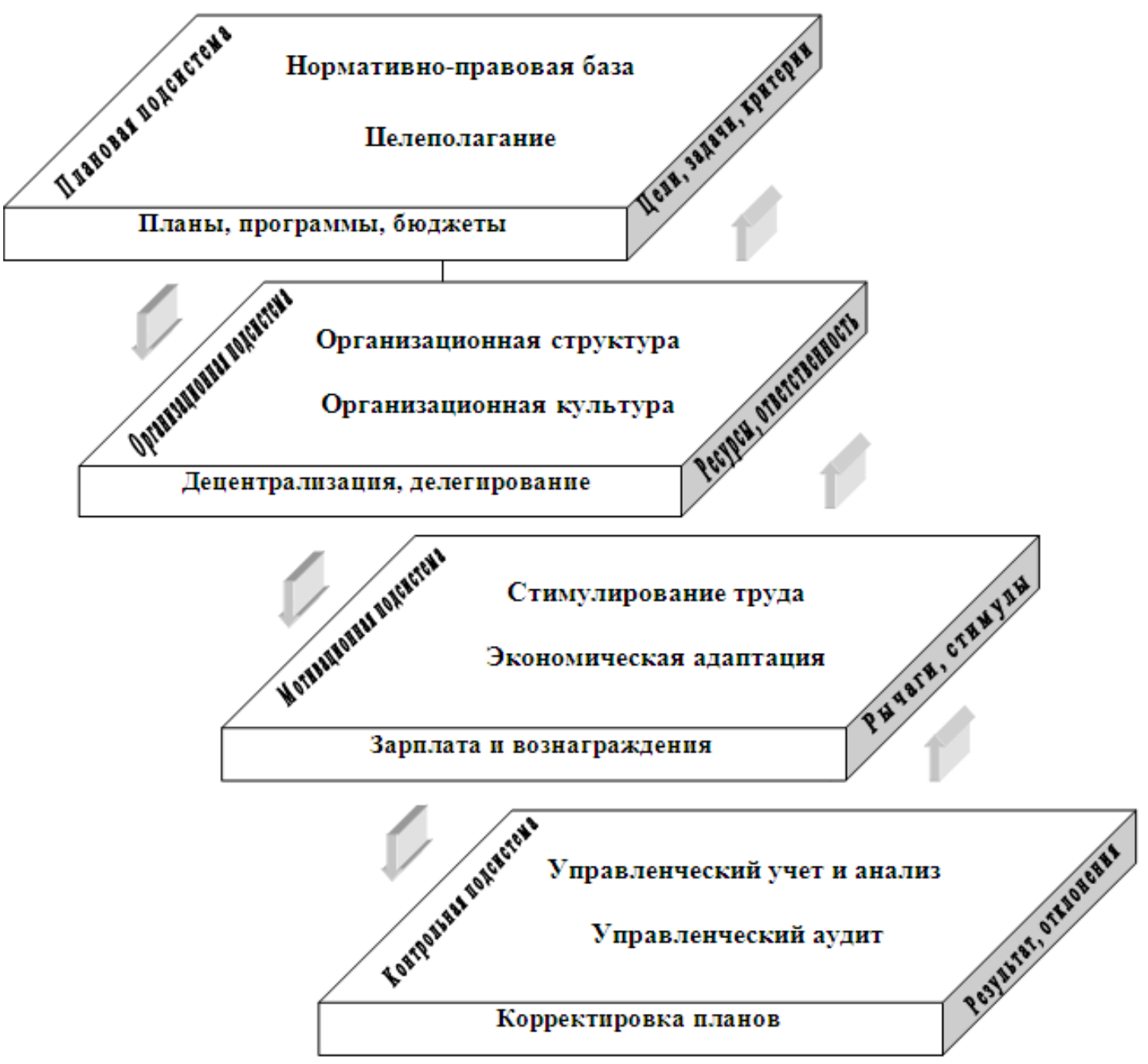

Puc. 2. Укрупненный механизм экономического управления предприятием 
ществляемые промышленными предприятиями, могут существенно отличаться по структуре затрат, прибыли, рентабельности, используемым активам. Хозяйственные операции могут осуществляться в неоднородных условиях внешней среды. Поэтому актуальным становится экономическое управление промышленными предприятиями в разрезе сегментов бизнеса.

В отечественной и зарубежной экономической литературе для обозначения такой организационной единицы как сегмент бизнеса используется термин «стратегическое хозяйственное подразделение» или стратегическая единица бизнеса (СЕБ), которые имеют следующие общие характеристики: конкретную ориентацию, точный целевой рынок, одного из руководителей во главе, контроль над ресурсами, собственную стратегию, четко обозначенных конкурентов, явное отличительное преимущество. В зависимости от целей и уровня экономического управления понятие сегмента бизнеса используются в трех значениях: продукт или группа продуктов (продукция, работы, услуги); центры ответственности; части внешней среды предприятия (географический регион, рынок сбыта, группа потребителей).

Между экономическим управлением предприятием в целом и управлением сегментами бизнеса существует ряд принципиальных различий:

1) сегменты бизнеса не имеют экономической самостоятельности, а находятся в административном подчинении у руководства предприятия;

2) приоритетными в деятельности являются цели функционирования предприятия, собственные цели сегмента бизнеса отодвигаются на второй план;

3) сегменты бизнеса самостоятельно осуществляют продажи только по указанию высшего руководства и др.

Для реализации методов экономического управления сегментами бизнеса промышленных предприятий необходимо создание таких условий работы, в которых они максимально заинтересованы в улучшении качества продукции и увеличении прибыли, например:

1) закрепление за сегментами бизнеса ресурсов, необходимых для их хозяйственной деятельности;

2) предоставление сегменту бизнеса оперативно-хозяйственной самостоятельности пу- тем наделения его руководства соответствующими полномочиями;

3) предоставление сегменту бизнеса права использовать заранее оговоренную часть прибыли по своему усмотрению;

4) применение штрафных санкций при невыполнении сегментом бизнеса своих обязательств и т.д.

П. Друкер утверждал, что «управлять можно только тем, что можно измерить» [11], поэтому актуальной задачей считаем определение эффективности механизма экономического управления промышленным предприятием. Ее решение предполагает формирование системы оценочных показателей, сгруппированных в плановую [12], организационную, мотивационную и контрольную функциональные подсистемы. Алгоритм оценки эффективности экономического управления сегментами бизнеса предприятия с применением соответствующего механизма приведен на рисунке 3.

На основе информации, подготовленной на этапах 1, 3, 5 и 7 алгоритма, рассчитываются четыре агрегированных показателя в разрезе функциональных подсистем механизма экономического управления сегментами бизнеса предприятия (рисунок 4):

$$
\mathrm{Bj}=\sum_{\mathrm{i}=1}^{\mathrm{kj}} \text { vij } \times \mathrm{Sij}
$$

где $\mathrm{k}_{\mathrm{j}}$ - количество показателей; $\mathrm{v}_{\mathrm{ij}}$ - значимость показателя; $\mathrm{S}_{\mathrm{ij}}$ - значение показателя.

Значения каждого из рассматриваемых показателей принимают балльные оценки от 1 до 10 (экспертная оценка). При установлении значимостей можно воспользоваться некоторыми рекомендациями. Например, если имеется только общая информация, которая позволит ранжировать показатели, то для определения весов можно использовать правило Фишберна. Более трудоемким, но обоснованным является применение метода парных сравнений.

Сформированные агрегированные показатели позволят дополнительно определить уровень риска как степень отклонения от желаемого состояния $\left(\mathrm{R}_{\mathrm{j}}=10-\mathrm{B}_{\mathrm{j}}\right)$, причем в таком случае, можно предвидеть, какая из четырех функциональных подсистем является в большей степени источником риска.

Имеющиеся агрегированные показатели позволят сформировать интегральный показатель эффективности механизма экономического 


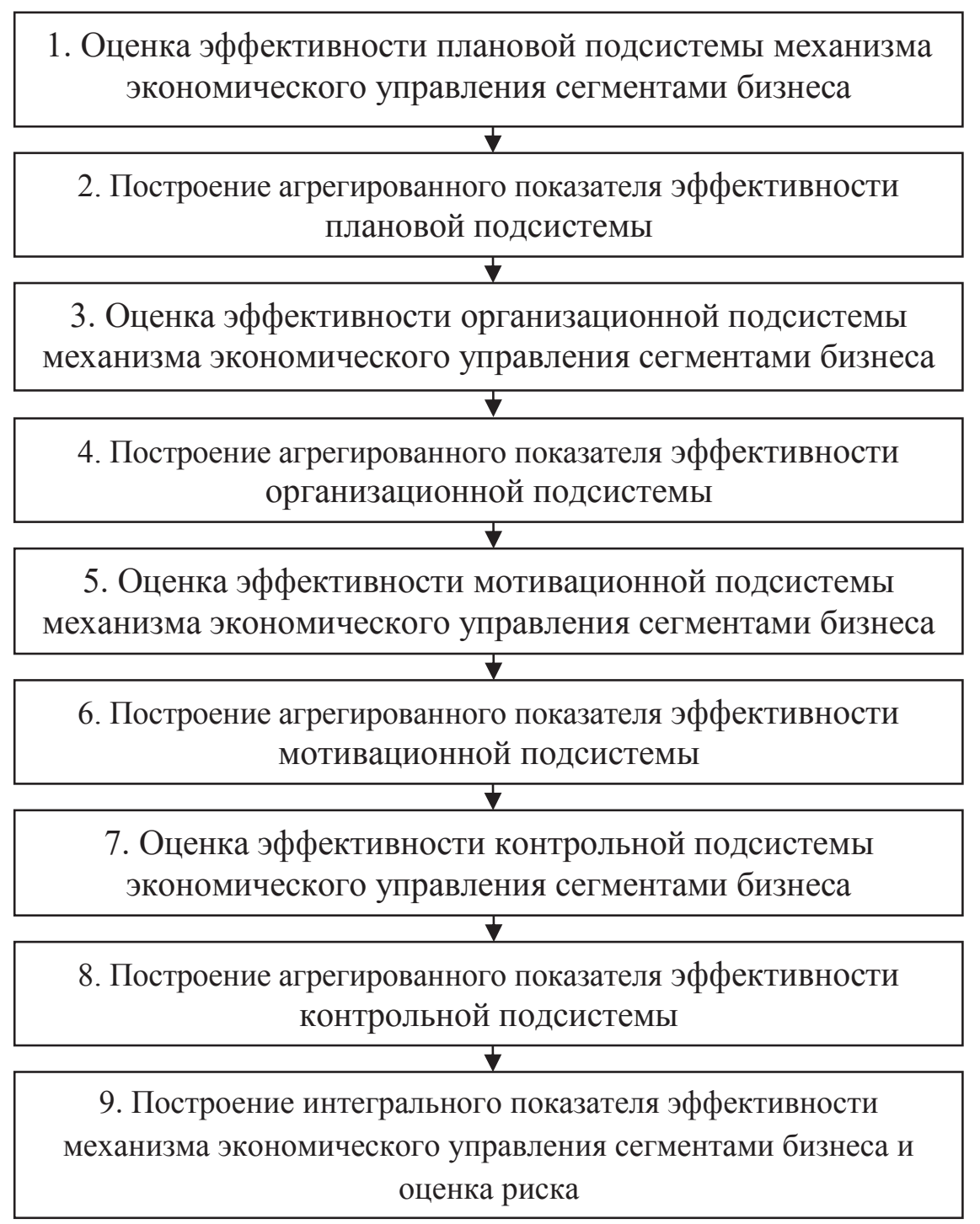

Puc. 3. Алгоритм оценки эффективности механизма экономического управления сегментами бизнеса промышленного предприятия

управления сегментами бизнеса:

$$
\mathrm{E}=\sum_{\mathrm{j}=1}^{4} \mathrm{Nj} \times \mathrm{Bj}
$$

где $\mu_{j}-$ значимость агрегированного показателя; $\mathrm{B}_{j}-$ значение агрегированного показателя.

Полученный комплексный показатель эффективности механизма экономического управления сегментами бизнеса может быть интерпретирован следующим образом: значения интегрального показателя в диапазоне [0-3,3] соответствуют низким значениям, [3,3-6,6] средним значениям, [6,6-10] - высоким значениям эффективности.

Особенностью выпускаемой продукции ООО «Тюльганский машиностроительный завод», на фактологических материалах которого произведена апробация предлагаемой методики, является четкая продуктово-рыночная ориентация, когда конкретный ее вид может быть предложен только определенным группам потребителей. Кроме того, по разным группам продукции различаются не только конкуренты, но и характер конкуренции. Поэтому в качестве основы выделения сегментов бизнеса целесообразным представляется использование критерия - «продукт или группа продуктов (продукция, работы, услуги)» единого назначения. Были выделены сегменты бизнеса: «Бурильное оборудование», «Дробильно-размольное оборудование», «Карьерные и шагающие экскаваторы».

Порядок расчета агрегированного показателя эффективности плановой подсистемы меха- 


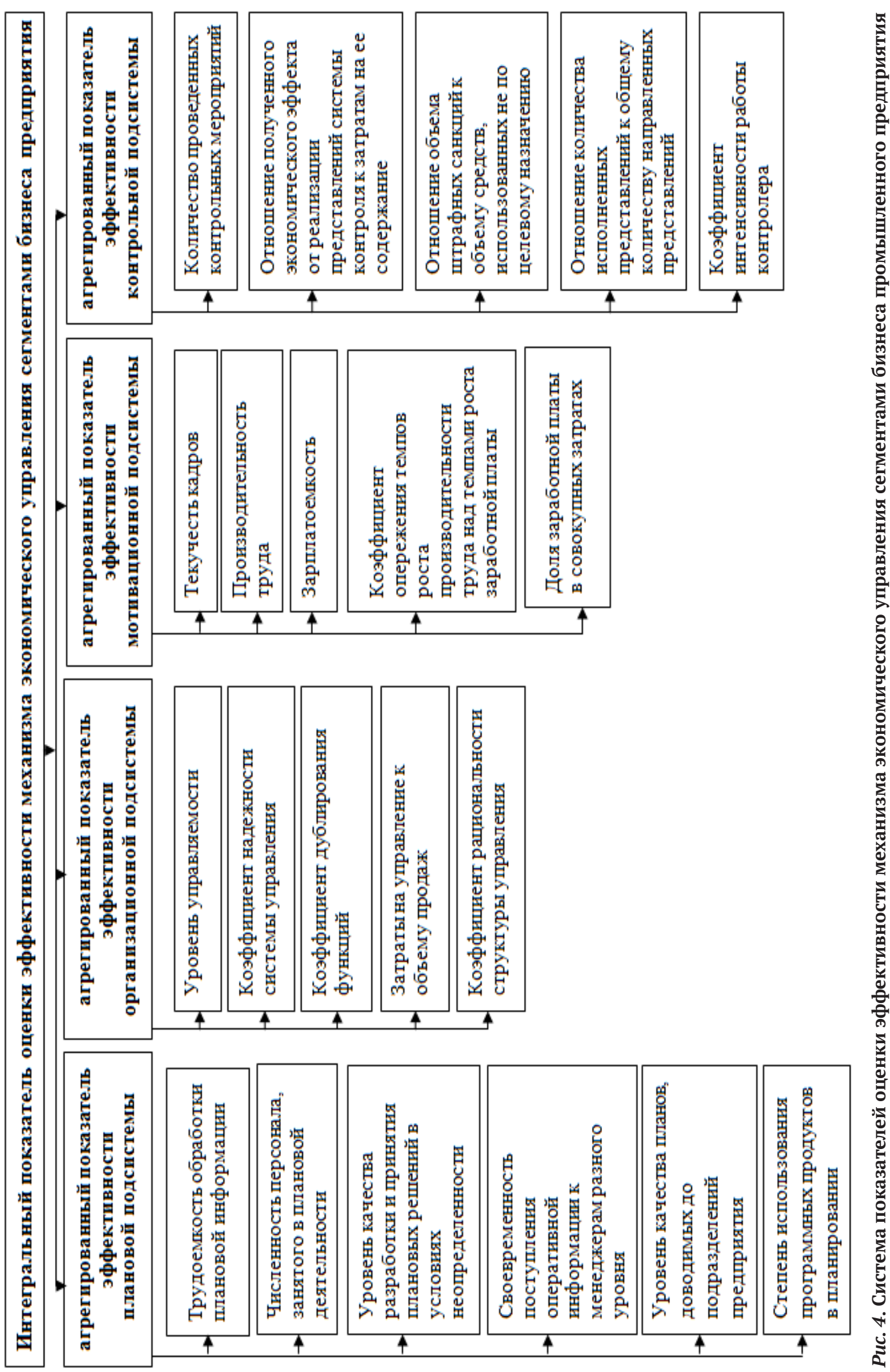


низма экономического управления сегментом бизнеса «Бурильное оборудование» представлен в табл. 1.

Аналогично осуществляется оценка эффективности организационной, мотивационной и контрольной функциональных подсистем механизма экономического управления и прочими сегментами бизнеса ООО «Тюльганский машиностроительный завод».

Порядок расчета интегрального показателя эффективности механизма экономического управления сегментами бизнеса представлен в табл. 2.

Значение интегрального показателя 7,789 входит в диапазон [6,6-10], что соответствует высоким значениям эффективности механизма экономического управления предприятием и его сегментами бизнеса, тем не менее, имеется достаточный потенциал для совершенствования.

Данная методика может использоваться многократно, причем как на этапе разработки механизма экономического управления сегмен-

Таблица 1. Расчет агрегированного показателя эффективности плановой подсистемы механизма экономического управления сегментом бизнеса «Бурильное оборудование»

\begin{tabular}{|c|c|c|}
\hline Наименование критерия & Значимость & $\begin{array}{c}\text { Оценка в } \\
\text { порядковой } \\
\text { шкале*) }\end{array}$ \\
\hline Трудоемкость обработки плановой информации & 0,1 & 8 \\
\hline Численность персонала, занятого в плановой деятельности & 0,1 & 6 \\
\hline $\begin{array}{l}\text { Уровень качества разработки и принятия плановых решений в условиях } \\
\text { неопределенности }\end{array}$ & 0,2 & 7 \\
\hline $\begin{array}{l}\text { Своевременность поступления оперативной информации к менеджерам } \\
\text { разного уровня }\end{array}$ & 0,2 & 8 \\
\hline Уровень качества планов, доводимых до подразделений предприятия & 0,2 & 7 \\
\hline Степень использования программных продуктов в планировании & 0,2 & 7 \\
\hline \multicolumn{2}{|l|}{ Агрегированный показатель эффективности плановой подсистемы, В1 } & 7,2 \\
\hline \multicolumn{2}{|l|}{ Оценка риска } & 2,8 \\
\hline
\end{tabular}

Таблица 2. Расчет интегрального показателя эффективности механизма экономического управления сегментами бизнеса

\begin{tabular}{|c|c|c|c|}
\hline Наименование & Значимость & Значение & Лингвистическая оценка \\
\hline $\begin{array}{l}\text { Агрегированный показатель эф- } \\
\text { фективности плановой подсистемы } \\
\text { механизма экономического управ- } \\
\text { ления сегментами бизнеса, В1 }\end{array}$ & 0,3 & 7,2 & $\begin{array}{l}\text { Значение показателя эффективности } \\
\text { входит в зону оценки «высокий», однако } \\
\text { отрицательные тенденции могут изменить } \\
\text { его на «средний» }\end{array}$ \\
\hline $\begin{array}{l}\text { Агрегированный показатель } \\
\text { эффективности организационной } \\
\text { подсистемы механизма экономи- } \\
\text { ческого управления сегментами } \\
\text { бизнеса, В2 }\end{array}$ & 0,2 & 8,15 & $\begin{array}{l}\text { Значение показателя уверенно позициони- } \\
\text { руется как «высокий» уровень эффектив- } \\
\text { ности }\end{array}$ \\
\hline $\begin{array}{l}\text { Агрегированный показатель } \\
\text { эффективности мотивационной } \\
\text { подсистемы механизма экономи- } \\
\text { ческого управления сегментами } \\
\text { бизнеса, B3 }\end{array}$ & 0,2 & 7,95 & $\begin{array}{l}\text { Значение показателя определяет «вы- } \\
\text { сокий» уровень эффективности, однако } \\
\text { необходимо отслеживать любые негатив- } \\
\text { ные тенденции, так как возможен переход } \\
\text { к «среднему» уровню }\end{array}$ \\
\hline $\begin{array}{l}\text { Агрегированный показатель эф- } \\
\text { фективности контрольной подси- } \\
\text { стемы механизма экономического } \\
\text { управления сегментами бизнеса, } \\
\text { В4 }\end{array}$ & 0,3 & 8,03 & $\begin{array}{l}\text { Значение показателя определяет «высо- } \\
\text { кий» уровень эффективности }\end{array}$ \\
\hline \multicolumn{2}{|c|}{$\begin{array}{l}\text { Интегральный показатель эффективности меха- } \\
\text { низма экономического управления сегментами } \\
\text { бизнеса, Е }\end{array}$} & 7,789 & $\begin{array}{l}\text { Значение интегрального показателя } \\
\text { уверенно позиционируется как «высокий» } \\
\text { уровень эффективности механизма эконо- } \\
\text { мического управления предприятием }\end{array}$ \\
\hline
\end{tabular}


тами бизнеса предприятия, так и на этапе его реализации. Применяемый в ней подход даст возможность определять «узкие места» в цикле экономического управления. Апробация предложенной методики промышленными предпри- ятиями позволит выявить их управленческий потенциал, реализовать который возможно используя современные методы экономического управления.

\section{Библиографический список}

1. Бюллетень о текущих тенденциях российской экономики.- Выпуск № 42.- октябрь 2018 г. -20 с. - Режим доступа: http://ac.gov.ru.

2. Факторы, ограничивающие деятельность организаций базовых отраслей экономики в 2017 году.- М.: НИУ ВШЭ, 2018-15 с.- Режим доступа: https://docviewer.yandex.ru.

3. Бездудная А.Г. Экономическое управление промышленным предприятием: учебник / А.Г. Бездудная, О.В. Кадырова, В.Г. Лебедев. Санкт-Перетбург. 2016. 230 с.

4. Коротков Э.М. История менеджмента: учеб. пособие / Э.М. Коротков, А.А. Беляев, Е. М. Трененков [и др.]; под ред. Э.М. Короткова. Москва. 2018. 240 с.

5. Жданов С.А. Методы и рыночная технология экономического управления. Москва. 1999. С.4; Гуськова М.Ф., Стерликов П.Ф., Стерликов Ф.Ф. Диалектика экономического прогресса // Экономические науки. 2006. № 7. C. 154 .

6. Рыжова В.В. Экономическое управление организацией: учеб. пособие / В.В. Рыжова, В.В. Петров. Москва. 2012. $248 \mathrm{c}$.

7. Ворст Й. Экономика фирмы: учебник / Пер. с датского А.Н. Чеканского, О.В. Рождественского. Москва. 1994. $272 \mathrm{c}$.

8. Суханов И.П. Вопросы повышения эффективности механизма управления промышленным комплексом и подходы к их решению / И.П. Суханов, Е.А. Коновалова // Экономика и финансы. 2006. № 5.

9. Спирина А.М. Исследование проблем организации и функционирования механизма стратегического планирования на предприятиях молочной промышленности // Молодой ученый, 2011. №9. С. 105-108.

10. Смирнова E.B. Модификация и аудит эффективности систем планирования промышленных предприятий в условиях конкуренции. Санкт-Петербург. 2011. 184 с.

11. Друкер, П. Задачи менеджмента в XXI веке. Москва. 2004. 272 с.

12. Панкова С.В. Аудит эффективности плановых систем промышленных предприятий / С.В. Панкова, Е.В. Смирнова // Экономический анализ: теория и практика, 2007. № 15 (96). С. 18-25. 